\title{
Research on the Problems and Countermeasures in the Course Construction of Military Academy
}

\author{
Wu-Di WEN \\ Academy of Weaponry Engineering, Naval University of Engineering,Wuhan430033,Hubei,China \\ 76769294@qq.com
}

Keywords: Curriculum Standards; teaching Echelons; Teaching Conditions.

\begin{abstract}
Five aspects of curriculum construction in military academies are summarized from the following aspects: curriculum standard, teaching material, teaching echelon, teaching methods and means, teaching conditions, and corresponding countermeasures are given.The problems such as insufficient implementation of the importance of curriculum construction, unreasonable curriculum, lack of timely updating of teaching materials, and lack of innovation in teaching methods and means are deeply analyzed. Finally, the specific ideas for the curriculum construction of military academies in the new era are given from three aspects: Quality requirements, teaching materials construction, teaching methods and means of the faculty team.
\end{abstract}

\section{Introduction}

The research of course construction has been the issues of concern to educators, the relevant literature is also very rich, covering all aspects of the curriculum construction, but the study for the construction of military colleges and universities curriculum lacks, especially in the face of the premise of new period military system reform, the whole educational institutions closer to the actual conditions, how to do a good job in military colleges and universities curriculum construction has become a new and important issues, urgent.

\section{The Main Contents of the Course Construction}

To understand the main contents of the course construction, the course should be understand accurate and comprehensive at first, Hong-xuan Liu defines the course as follows in the literature "Three relations of curriculum construction”: “A specific blueprint for training future talents are standardized school education activities composed of specific training objectives, basic cultural achievements and diversified teaching behavior, the media to guide the overall development of the students”[1]. According to this definition, curriculum construction is usually divided into five aspects: curriculum standard construction, teaching material construction, teaching echelon construction, teaching method and means construction, teaching condition construction and so on.

\section{Construction of curriculum standards}

The curriculum standard is about the overall design of the curriculum. It is a programmatic document guiding the construction and teaching of the colleges and universities. It is the standard and quality requirement of the course ${ }^{[2]}$. At present, with the continuous advance of our military system reform and the deepening of teaching reform practice, new and higher requirements for the construction of curriculum standards are put forward, the construction of the curriculum standards must be aimed at the demand for the position of the graduates in the military equipment development and the actual combat training, scientific arrangement of teaching content, reasonable determination of teaching requirements, continuous innovation of teaching methods and means to ensure the quality of curriculum standard construction; At the same time, the working mechanism of the dynamic revision of the curriculum standard is set up, and the curriculum standard is adjusted and modified according to the implementation of the curriculum standard and the demand of the troops. 


\section{The construction of teaching materials}

In view of the course of military academies, the construction of teaching materials is the goal of the general requirements for the training of the personnel in demand for the post of military posts. According to the characteristics of different structure of professional curriculum knowledge system, constantly to new knowledge, new content, new equipment, new methods and new training methods to enrich the teaching materials, refined classic content, the elimination of obsolete content, and effectively improve the curriculum system, scientific and advanced, so that the development of teaching materials to meet the practical requirements of cultivating talents.

\section{The construction of teaching echelons}

The construction of teaching echelons is a decisive factor in the course construction, so-called" It takes ten years to grow trees but a hundred years to rear people”, other things can be built in a short period of time, but the construction of the talent team is not a day and night. It includes the basic structure of the faculty, the teaching ability of the teachers, the level of scientific research, the basic quality and the development of the teaching team. The goal of teaching echelon construction is to establish a team of teachers with reasonable age structure, strong teaching ability, high academic level and dedication to national defense.

\section{Construction of teaching methods and means}

At present, the construction of teaching methods and means is mainly from the traditional methods and means to the use of modern educational technology. Therefore, we need to strengthen the reform of teaching methods, actively adopt heuristic, discussion, research and cooperation methods to teach, from spoon feeding to lectures, emphasis and methods. Actively use the multimedia teaching means, enrich the content to increase the amount of information, mobilize the enthusiasm and initiative of the students to study. Developing a high level multimedia courseware and setting up a MOOC teaching platform on the Internet. Increase the database construction, the establishment of performance analysis and test quality analysis system, to explore the implementation of students throughout the examination performance evaluation method, and gradually realize the students test scores by single semester, school year assessment to change until the whole comprehensive evaluation.

\section{The construction of teaching conditions}

Teaching conditions are the material basis for normal operation of teaching activities. The school level mainly includes teaching infrastructure, such as classroom, laboratory, training field, practice base, library and campus network. To the level of teaching units, the construction of teaching conditions mainly refers to the construction of specialized laboratories, specialized classrooms, laboratory equipment and equipment, archival materials, books and magazines, teaching facilities and so on.

\section{The problems of curriculum construction in military colleges and universities are easy to exist}

Curriculum construction is an important basic task of military academies, quality plays a decisive role in cultivation of talents in colleges need to persevere firmly grasp. In recent years, subject to the influence of the restructuring and adjustment of the army system, the following problems are likely to occur in the course construction.

\section{The importance of the importance of curriculum construction is not enough}

The course construction is the most basic, most frequent and important task of the teaching units at all levels in the military colleges and universities. The importance of the course construction is beyond doubt, we generally recognize, but in fact, some of the basic department of basic work speaks more implement less importance to its understanding of stay in the mouth, as a daily work to deal with the phenomenon is relatively common. Some units have not been put into an important curriculum 
construction schedule of teaching reform, not fully aware of the course construction of the core status in the teaching reform in the course of the construction of the target, the lack of accurate positioning, the connotation of curriculum construction of the lack of correct understanding, lack of in-depth thinking of the curriculum construction planning, grasp the course construction achievements is not obvious.

\section{The course setting is not reasonable enough}

The irrational course setting limits the benefit of the course construction at the source. At present, a common problem is that there is no access system in the curriculum. There is no strict and scientific argument in the curriculum. Some units are even in a state of disorder, resulting in a relatively poor scientific and standardized curriculum construction. For example, the phenomenon of setting up classes and repeating courses is common. Some units dismantle the curriculum, resulting in the fragmentation of the curriculum knowledge system, the intersecting and discontinuous content of the content, the low teaching efficiency and the low learning efficiency of the students. There are also teaching offices that emphasize the importance of their own unit courses, compressing other unit courses, competing for courses and competing for class hours.

\section{The content of the textbook is not updated in time}

Whether in basic courses or professional courses, the content of knowledge system has a stable aspect, but the reality is that knowledge update is faster and faster, and textbook updating is not always enough. On the basis of class with classical courses as the representative of the proposed new requirements, need to use modern ideas, ideas to teach young students some classical theory; the professional class, and are directly related to military equipment, the update speed faster and the corresponding teaching content should also be updated timely, must not lag behind the troops the development and construction of practical training equipment.

\section{Lack of innovation in teaching methods and means}

Teaching methods and means are the ties linking teaching and learning closely. It is the basic way to achieve the goal of curriculum teaching. The good methods and means can arouse the enthusiasm of the students, arouse the enthusiasm of the students, and play a double effect on the study of the course content. But at present colleges and universities teaching supervision group members of professional knowledge can not understand, most do not grasp of new equipment, to check the class demands on teachers on teaching form, leading teachers to the teaching methods and means of reform is not positive, the traditional teaching method is still the mainstream, even some courses using discussion case type teaching mode, but most of them are lack of system, the students did not attach importance to the cultivation of professional competence, the overall effect is not ideal.

\section{The Countermeasures of the curriculum construction of military colleges and universities in the new period}

After the adjustment and reform of the military academy's compilation system in the new era, the military academies' curriculum construction should stand at a higher starting point and have higher requirements, and should shoulder the responsibility of training better qualified personnel for front-line positions in the army. The following are the preliminary discussion from three aspects: the quality requirements of the faculty, the construction of teaching materials, the methods and means of teaching.

\section{Requirements for the ability and quality of the faculty}

Knowing it, we should also know that it is one of the goals to be achieved in the course of course learning. This requires teachers to have a solid theoretical foundation first, so that through their own learning, we can quickly and thoroughly grasp the theoretical knowledge needed for teaching. Secondly, the teachers should always pay attention to the development of the troops and master the 
equipment of the army systematically and comprehensively. The equipment is the foundation of the professional post, and the course teaching must be close to the new equipment. Equipment to be a system, a system to be a confrontation, is the information war on the requirements of weapons and equipment, at present, weaponry is developing towards a systematized and systematized direction. Generally speaking, the new equipment is a complete set of equipment system composed of several subsystems, which requires multiple professionals and various personnel to cooperate with each other to operate properly. In the course of teaching, a course may only undertake a subsystem or even a part of the task of teaching, but the explanation cannot be separated from the whole equipment subsystem or component, must pay attention to the connection between various subsystems and close cooperation, to enable students to master the handling charge equipment the overall knowledge and ability. This requires the teachers to form the concept of the equipment as a whole, to understand the equipment from a systematic point of view, and to grasp the essence of the equipment.

\section{The construction of teaching materials}

The teaching material is the main carrier of the course construction. It is a teaching book which is compiled on the basis of the curriculum standard and systematically responds to the content of the course. It is the concretion of the curriculum standard. Therefore, before the construction of teaching materials, we should familiarize ourselves with curriculum standards, clarify the purpose and guiding ideology of textbook construction, and determine the scope, framework and key points of textbook construction. The teaching material construction of military academies in the new period can start from the following three aspects:

\section{Focus on the demand of the army and improve the gold content of the teaching materials}

What kind of talent is needed in the army and what kind of students should be trained by military academies. Compared with the ordinary local universities, cadets in management education and training, to take up more time, which requires the construction of teaching materials to do fine, simple and practical in teaching contents should be selected carefully, remove redundant parts, knowledge points of penetration, to tell the truth, close to the reality of the army, through the build quality of teaching materials, fine notes, software products, enhance the quality of teaching materials.

\section{Follow up the military reform and highlight the new content of the textbook}

In the course of the construction of teaching materials, we should always stand at the forefront of the military reform. Especially for the construction of professional courses, we need to update textbooks in the field of military expertise, including new knowledge, new technology, new equipment and new tactics. On the one hand, we should fully absorb the latest achievements of modern science and technology and academic research, especially the successful experience of army training reform, and the corresponding curriculum contents should be updated in a timely manner, so we must never lag behind the changes in the development of military equipment and the way of training. On the other hand, teachers should accumulate knowledge and actively participate in curriculum related equipment research and training, do the main body of curriculum knowledge accumulation and innovation, and lay a solid foundation for teaching material construction.

\section{Adhere to the actual combat of the army and strengthen the amount of war in the teaching materials}

The troops are training combat training, colleges and universities also advocated the transformation of teaching to actual combat, which requires the construction of teaching materials should be required and comprehensive ability closely around the cadets' first post the increase in military positions need to solve the problem as the center, to break the traditional intellectual discipline boundaries, restructuring the knowledge system, comprehensive and practical outstanding teaching materials. To keep pace with future operational needs, we need to closely follow the needs of the army's reform and readjustment and operational mission in the new era. We should closely follow the development 
needs of weapons and equipment, ensure the practicality and pertinence of teaching materials, and enhance the volume of battles involved.

\section{Teaching methods and means}

The teaching method is the use of knowledge in the teachers under the control of method to enable students to become qualified talents, achieve the purpose of teaching, its essence is determined in accordance with the teaching objective by teachers to impart knowledge, to complete the task of teaching, training of qualified personnel of the bilateral activities between teachers and students, the role of the object is students, it is a method to promote the all-round development of students, teachers play the leading role in the use of teaching methods in. Many kinds of teaching methods, different teaching methods are the advantages and disadvantages of There are both advantages and disadvantages., but only with respect to specific teaching objectives, teaching content and teaching object. The value of a teaching method varies with many different teaching factors. Therefore, in practical teaching, there are often organic combinations of various teaching methods, and different teaching methods should be chosen properly and rationally for different teaching contents and objects.

Teaching means is an important tool to improve teaching quality. Aiming at the needs of practical teaching, we combine multiple teaching methods to combine the advantages of traditional teaching methods and modern teaching methods. It is the best choice to be able to use practical equipment for teaching and to enable the seamless docking of the classroom and the battlefield. In the absence of actual conditions, to the reasonable development and application of modern teaching equipment, training students as much as possible to feel real, realizing the combination of theory and practice, through the use of simulation training equipment, familiar with equipment operation, equipment to eliminate students' sense of fear and strangeness; use of teaching equipment, teaching equipment can be the principle. The abstract principle concretely and figuratively; use the 3D model and the virtual equipment software, can each part of the equipment for visual decomposition, deepen understanding of the equipment.

\section{References}

[1] H. X. liu. On the three relations of curriculum construction, Naval Academy Education,Vol.5,14-18,2002.

[2] B. Y. Gao,Z. X. Wang. To explore the new perspectives of education in Military Academies, Liberation Army press,Beijing,China,105,2006.

[3] P. Liu,S. L. Zheng. Research on improving the teaching ability of new equipment, Continuing Education,Vol.3,30-32,2013. 